\title{
Notes on records of Trochulus hispidus (Gastropoda: Hygromiidae) feeding with an exotic Gymnosporangium sabinae (Basidiomycota: Pucciniaceae) in Latvia
}

\author{
Arturs Stalažs*, Baiba Lāce \\ Institute of Horticulture, Latvia University of Life Sciences and Technologies, Graudu 1, Cerinii, Krimūnu pagasts, Dobeles novads \\ LV-3701, Latvia \\ *Corresponding author, E-mail: arturs.stalazs@llu.lv
}

\begin{abstract}
Feeding with the telia structures of an exotic fungus species Gymnosporangium sabinae (Dicks.) G. Winter (1884) (Basidiomycota: Pucciniaceae) by the native snail species, Trochulus hispidus (Linnaeus, 1758) (Gastropoda: Hygromiidae), was documented in spring of 2015 and 2016 in Latvia. In both years snails fed with G. sabinae in field conditions at a home garden at Dobele (Latvia). T. hispidus generally preferred initial structures of G. sabinae telia before these structures developed as orange gelatinous mass, when fungus lost its attraction as potential food for T. hispidus snails.
\end{abstract}

Key words: common hairy snail, feeding behaviour; exotic fungus.

\section{Introduction}

The common hairy snail, Trochulus hispidus (Linnaeus, 1758), is highly variable and is the most widely distributed Trochulus species in Europe. Snails mainly live in different types of damp habitats and in summers climb on specific plants (Proćków 2009). These snails are very common in urbanised environments and cities, a. g. villages and cities (Shikov 1979) Recently several works have been dedicated to T. hispidus, including one report on its avian dispersal and one report on Haemopis sanguisuga (Linnaeus, 1758) feeding with T. hispidus (Dépraz et al. 2009; Duda et al. 2011; Shikov 2011; Proćków et al. 2012; Rusiecki, Rusiecka 2013; Proćków et al. 2013; Kruckenhauser et al. 2014; Shepeleva 2014; Proćków, Kuźnik-Kowalska 2016).

According to Proćków et al. (2013) the only published account on T. hispidus diet has been by Frömming (1954), which provides both results of diet in natural habitats and results from experimental studies. In this study living plants, fruits, roots and mushrooms were used as food for $T$. hispidus. It was shown that $T$. hispidus willingly consumes mushrooms, but usually mushrooms are not the preferred food source of different slugs. A remarkable number of excrement samples from snails collected in different habitats were analysed, and microscopic fungi, e. g. Alternaria and Fusarium conidia and spores, Puccinia simplex (now Puccinia hordei) teleitospores, spores of other fungi and parts of lower fungi were also found (Frömming 1954). Food preferences of T. hispidus have been tested recently in laboratory conditions by offering decaying dead leaves of Fraxinus excelsior, Acer platanoides, Acer pseudoplatanus and Tilia cordata (Proćków et al. 2013). Unfortunately, during later studies food preference of $T$. hispidus was not analysed in field conditions. Although $T$. hispidus seems to be often studied, nevertheless most of the studies have been focused on its life-cycle and reproductive biology, not feeding behaviour.

The wider available data published by Frömming (1954) allows to conclude that in natural habitats T. hispidus gives preference to rotting plant material, fungi, pollen, but living plants probably are in second place of food choose. Interestingly, Frömming (1954) in a number of cases was able to identify living plants such as Urtica sp. as food. Among plants, live Urtica sp. in contrast to other living plants usually is an exception for another well studied snail species, Cepaea nemoralis, and together with mosses this food is eaten in noticeable amounts (Wolda et al. 1971; Richardson 1975).

The present paper reports cases of T. hispidus feeding on fungus Gymnosporangium sabinae (Dicks.) G. Winter (1884), which was observed during monitoring of the development of G. sabinae in conditions of Latvia.

\section{Materials and methods}

The development of Gymnosporangium sabinae was observed regularly and documented in spring in 2014, 2015 and 2016. In one of monitoring sites, at a private garden in Dobele (Latvia) the feeding of Trochulus hispidus on G. sabinae telia structures on three infested Juniperus sabina plants was documented. 


\section{Results and discussion}

The fungus species Gymnosporangium sabinae has exotic origin, and first appeared in Latvia it in late 1990-ies (Lāce 2017). To complete its life cycle, G. sabinae needs two different hosts (Fraiture, Vanderweyen 2011). The primary hosts are some specific Juniperus species, e.g. Juniperus chinensis, Juniperus $\times$ pfitzeriana, Juniperus sabina and Juniperus virginiana [Gjærum et al. 2008; Fraiture, Vanderweyen 2011; R. Strelčūns (personal communication 2017)], on which G. sabinae overwinters and in spring produces telia structures, later becoming an orange gelatinous mass (Fig. 1).

In spring in 2015 and 2016, it was documented that Trochulus hispidus snails fed on G. sabinae fungus growing on J. sabina. The individuals of T. hispidus in the garden occurred numerously. By consuming this fungus, the snails even removed its young telia structures from Juniperus stems (Fig. 1, 2). T. hispidus fed on telia structures of this fungus generally in its initial development phase, before telia structures developed as orange gelatinous mass.

When telia structures of this fungus were already large orange gelatinous mass, T. hispidus almost did not showed interest about fungus. Later (observed only in 2016), a few specimens of another snail species, Arianta arbustorum (Linnaeus, 1758), were observed on these orange gelatinous mass structures.

The fact that feeding with G. sabinae in natural (not laboratory) conditions was observed in two consecutive years demonstrates that $T$. hispidus willingly consumes this fungus species. Direct observations on snail feeding is the most straightforward method, but sometimes this method has mistakes, as it is often difficult to decide if snails indeed are feeding (Speiser 2001). As the G. sabinae telia structures are quite large in size, it allowed easy feeding documentation. Though T. hispidus is highly common species in a large part of Europe, its feeding with particular organisms, especially microscopic ones, in natural conditions still remains insufficiently known.

Graham (1955) in his literature review provides published data about mollusc feeding, and for many land gastropods, different plants have been reported as food, including "crop plants" for a related species, Trichia striolata (now Trochulus striolatus). It seems that in many cases the plants are presumed food, not confirmed food, especially for T. hispidus. Frömming's (1954) findings demonstrate that the diet of T. hispidus is diverse, but different fungi, rotting plant parts are of the main preference, but living plants much rarely used, except Urtica sp. plants, which is the main food source if these plants dominate in the particular habitat. Proćków et al. (2013) demonstrated that in laboratory conditions T. hispidus snails differently used offered food (decaying leaves), and this difference were observed between adult and juvenile snails; adult snails preferred Fraxinus excelsior leaves over other offered plant leaves, but juveniles equally consumed leaves of all offered plants. Speiser (2001) suggested that senescent plant material is often used by gastropods as this food has low

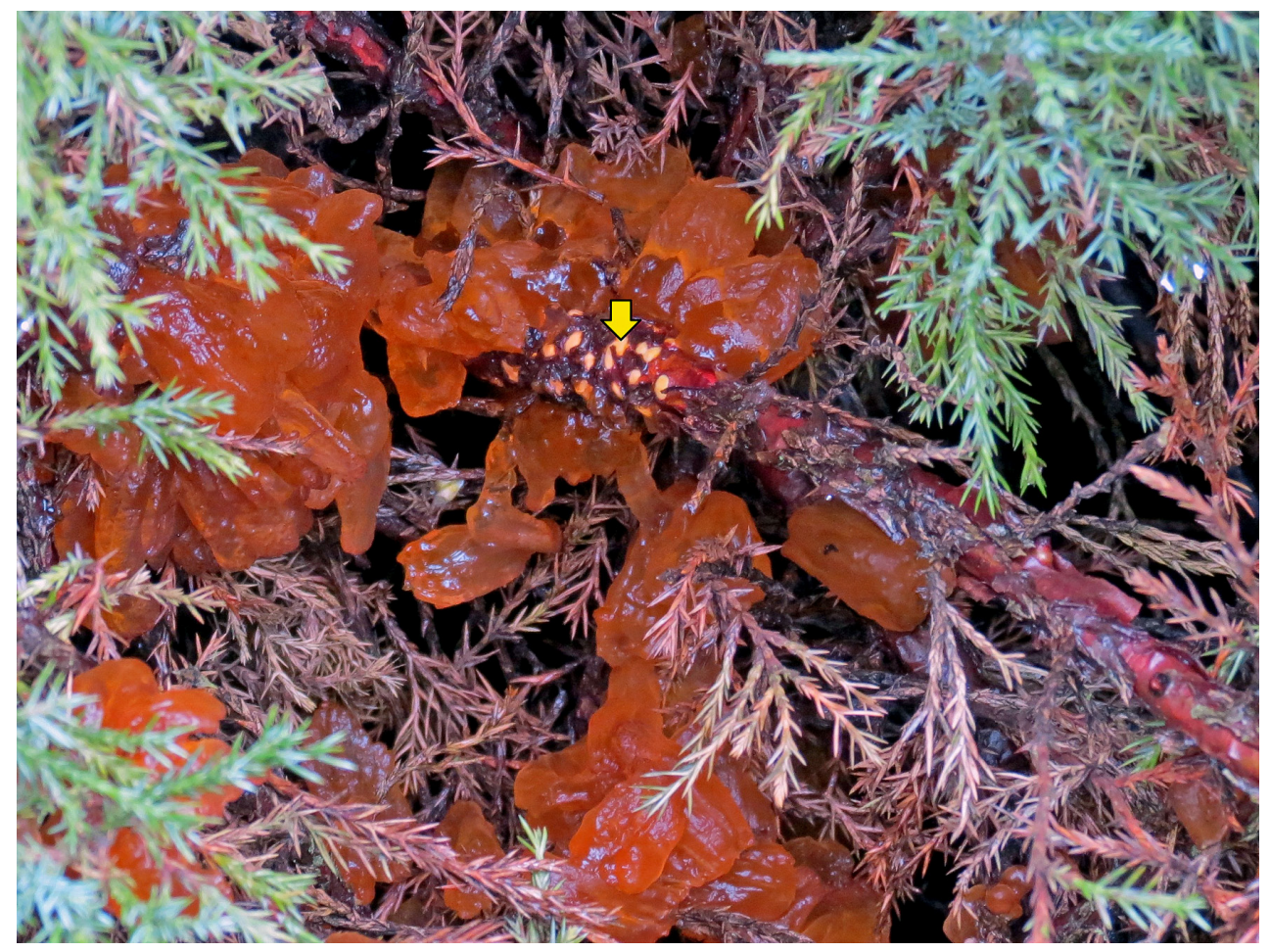

Fig. 1. Orange and soft gelatinous telia structures on Juniperus sabina stems, and part of telia structures consumed by Trochulus hispidus snails: the light spots shown with arrow (photo by B. Lāce on May 16, 2016). 


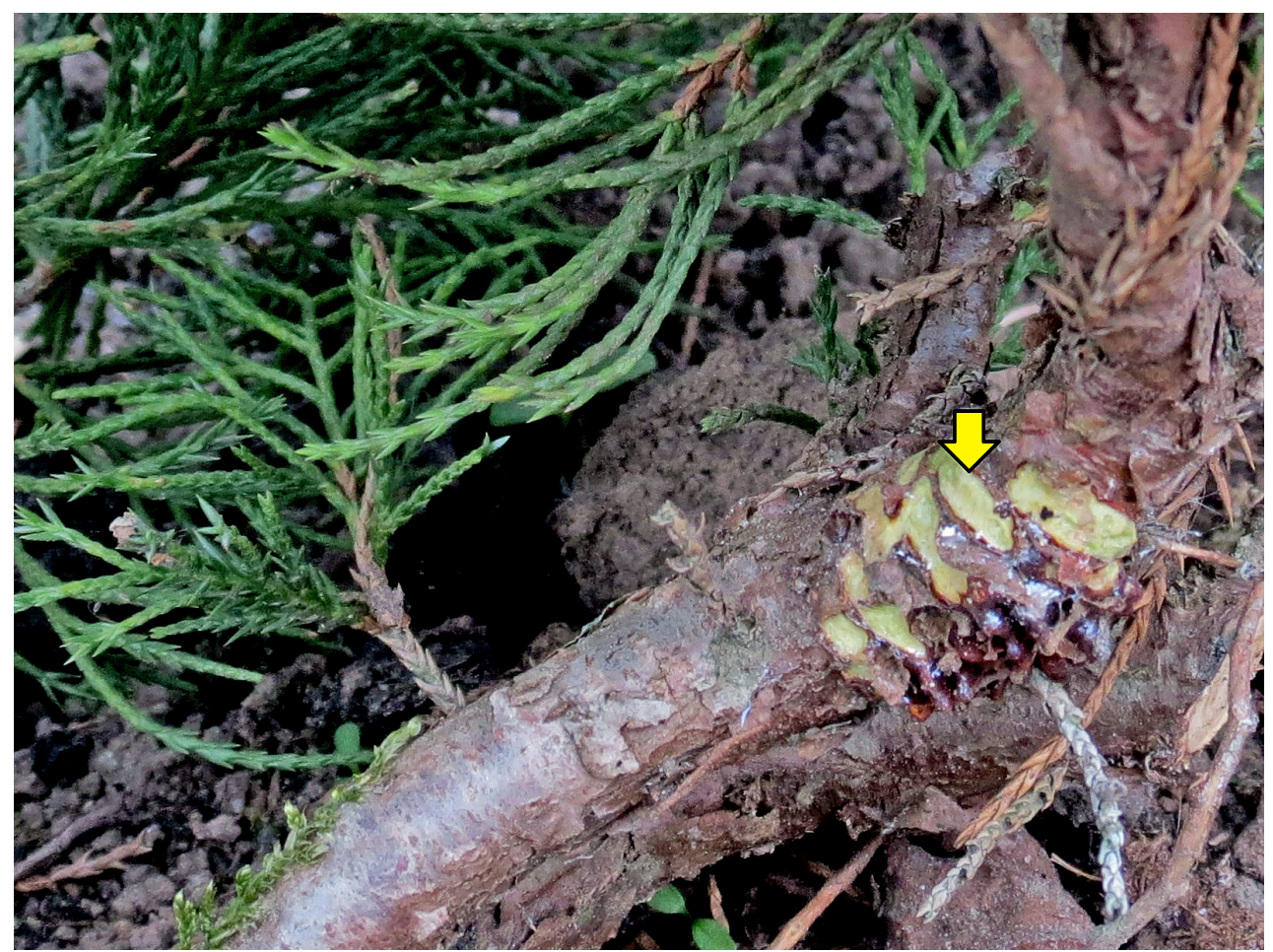

Fig. 2. Telia structures on Juniperus sabina stem in its early phase of development completely consumed by Trochulus hispidus snails. The light spots shown with arrow are places where started development of initial Gymnosporangium sabinae telia structures (photo by B. Lāce on April 28, 2015).

toxin content. However since senescent plant parts start to decay, microscopic fungi always will promote this process causing the feeding interest to many gastropod species, including T. hispidus. During the last 22 years of research in Latvia, frequent complaints have been received from owners of home gardens, as citizens frequently presumed that T. hispidus occurring on plants in their gardens are serious plant pests that should be destroyed. These presumptions wrongly assume that the resting of snails is frequently connected with a food source, and not with plants as a resting place. Although it is not important in the case of common species, like T. hispidus, but in cases with rare species similar incorrect presumptions can cause damage to particular species as they could be eliminated as "presumed" and undesirable pests.

\section{Acknowledgements}

The authors thanks Małgorzata Proćków (Poland) for help with older literature, and Edgars Dreijers (Latvia) for valuable comments and literature information translation from German.

\section{References}

Dépraz A., Hausser J., Pfenninger M. 2009. A species delimitation approach in the Trochulus sericeus/hispidus complex reveals two cryptic species within a sharp contact zone. BMC Evol. Biol. 9: 171.

Duda M., Sattmann H., Haring E., Bartel D., Winkler H., Harl J., Kruckenhauser L. 2011. Genetic differentiation and shell morphology of Trochulus oreinos (Wagner, 1915) and $T$. hispidus (Linnaeus, 1758) (Pulmonata: Hygromiidae) in the northeastern Alps. J. Moll. Stud. 77: 30-40.

Fraiture A., Vanderweyen A. 2011. Gymnosporangium sabinae: such a beautiful disease... Scr. Bot. Belgica 47: 193-194.

Frömming E. 1954. Biologie der mitteleuropäischen Landgastropoden. Duncker \& Humblot, Berlin.

Gjærum H.B., Gauslaa Y., Talgø V. 2008. Gymnosporangium sabinae found in Norway. Plant Pathol. 57: 376.

Graham A. 1955. Molluscan diets. Proc. Malacol. Soc. London 31: 144-159.

Kruckenhauser L., Duda M., Bartel D., Sattmann H., Harl J., Kirchner S., Haring E. 2014. Paraphyly and budding speciation in the hairy snail (Pulmonata, Hygromiidae). Zool. Scr. 43: 273-288.

Lāce B. 2017. Gymnosporangium species - an important issue of plant protection. Proc. Latv. Acad. Sci. B 71: 95-102.

Proćków M. 2009. The genus Trochulus Chemnitz, 1786 (Gastropoda: Pulmonata: Hygromiidae) - a taxonomic revision. Folia Malacol. 17: 101-176.

Proćków M., Drvotová M., Juřičková L., Kuźnik-Kowalska E. 2013. Field and laboratory studies on the life-cycle, growth and feeding preference in the hairy snail Trochulus hispidus (L., 1758) (Gastropoda: Pulmonata: Hygromiidae). Biologia 68: 31-141.

Proćków M., Kuźnik-Kowalska E. 2012. An anomaly of the reproductive organs in Trochulus hispidus (Linnaeus, 1758) (Gastropoda: Pulmonata: Hygromiidae). Folia Malacol. 20: 39-41.

Proćków M., Kuźnik-Kowalska E. 2016. Major fitness components in life history of euryoecious land snail Trochulus hispidus (Linnaeus, 1758) (Gastropoda: Hygromiidae). Folia Malacol. 
24: $179-184$.

Richardson A.M.M. 1975. Food, feeding rates and assimilation in the land snail Cepaea nemoralis L. Oecologia 19: 59-70.

Rusiecki S., Rusiecka A. 2013. Hairy snail Trochulus hispidus (Linnaeus, 1758) in flight - a note on avian dispersal of snails. Folia Malacol. 21: 111-112.

Shepeleva I.P. 2014. A comparative analysis of the camera eyes of gastropod pulmonate mollusk Trochulus hispidus (Linnaeus, 1758) from the South Sweden and Kaliningrad Region (Stylommatophora, Hygromiidae). Ruthenica 24: 123-127./in Russian/

Shikov E.V. 1979. The fauna of land molluscs on populated areas of the Valdai Hills and adjecent territories. Zool. Zhurnal 58: 969-976. /in Russian/

Shikov E.V. 2011. Haemopis sanguisuga (Linnaeus, 1758) (Hirudinea) - the first observation of a leech predation on terrestrial gastropods. Folia Malacol. 19: 103-106.

Speiser B., 2001. Food and feeding behaviour. In: Barker G.M. (ed) The Biology of Terrestrial Molluscs. CABI Publishing, Oxon, pp. 259-288.

Wolda H., Zweep A., Schuitema K.A. 1971. The role of food in the dynamics of populations of the landsnail Cepaea nemoralis. Oecologia 7: 361-381. 